STUDI

FRANCESI

\section{Studi Francesi}

Rivista quadrimestrale fondata da Franco Simone

183 (LXI | III) | 2017

Varia

\title{
C. Bonn, Lectures nouvelles du roman algérien. Essai d'autobiographie intellectuelle
}

\section{Elena Fermi}

\section{(2) OpenEdition}

1 Journals

\section{Édition électronique}

URL : http://journals.openedition.org/studifrancesi/10614

DOI : 10.4000/studifrancesi. 10614

ISSN : 2427-5856

Éditeur

Rosenberg \& Sellier

\section{Édition imprimée}

Date de publication : 1 décembre 2017

Pagination : 591-592

ISSN : 0039-2944

\section{Référence électronique}

Elena Fermi, «C. Bonn, Lectures nouvelles du roman algérien. Essai d'autobiographie intellectuelle », Studi Francesi [En ligne], 183 (LXI | III) | 2017, mis en ligne le 01 février 2018, consulté le 26 janvier 2021.

URL : http://journals.openedition.org/studifrancesi/10614 ; DOI : https://doi.org/10.4000/

studifrancesi. 10614

Ce document a été généré automatiquement le 26 janvier 2021.

\section{(c)}

Studi Francesi è distribuita con Licenza Creative Commons Attribuzione - Non commerciale - Non opere derivate 4.0 Internazionale. 


\title{
C. Bonn, Lectures nouvelles du roman algérien. Essai d'autobiographie intellectuelle
}

\author{
Elena Fermi
}

\section{RÉFÉRENCE}

CHARLES BONN, Lectures nouvelles du roman algérien. Essai d'autobiographie intellectuelle, Paris, Classiques Garnier, 2016, 282 pp.

1 Charles Bonn mène, dans ce riche ouvrage, une sorte d'enquête autour du roman algérien, dont il est l'un des principaux spécialistes en France. Son but est celui de faire le point, plus de quarante ans après ses débuts, sur l'évolution de sa lecture de ce phénomène littéraire. Le volume est en effet un recueil d'articles et de communications qui témoignent de cette évolution. Dans une longue introduction, l'auteur trace une sorte d'autobiographie intellectuelle et rend compte des différentes étapes à travers lesquelles il a dû passer pour construire sa vision actuelle du sujet traité. Quelques points de repères commencent à y être fixés. Le roman algérien serait essentiellement le produit de la décolonisation, avec tout ce qu'elle a entraîné et signifié dans ce pays, et son histoire commencerait, de ce fait, au cours des années cinquante. Ce roman subvertirait le modèle hérité du xIX ${ }^{e}$ siècle français, subversion littéraire mais aussi politique, car elle viserait un symbole de la colonisation. Sa littérarité, enfin, serait à rechercher ailleurs que dans le roman occidental traditionnel, dans la perturbation des chronologies, dans l'incertitude sur l'identité des narrateurs, dans la juxtaposition de récits sans lien apparent les uns avec les autres, dans le rapport à l'Histoire, dans l'opposition de l'espace rural à l'espace citadin, dans la dimension tragique.

2 Les quatre parties dans lesquelles est divisé le présent volume rendent compte des différents axes de la recherche de l'auteur, qui a choisi de laisser de côté toutes les réflexions précédant 1984 pour privilégier les approches les plus actuelles sur le plan 
théorique. Le corpus qu'il a décidé de prendre en compte, en revanche, comprend essentiellement des textes qui sont devenus des grands «classiques» de cette littérature. Comme il s'agit d'ouvrages ayant bénéficié d'une certaine notoriété au niveau universitaire, donc d'un certain nombre d'études, ils représentent le meilleur corpus pour montrer l'évolution de la recherche et des approches de l'auteur.

3 La production de l'Histoire est consacrée notamment au rapport du roman algérien avec la guerre d'Algérie et tente de mettre en lumière la tentative, en partie échouée, de construire, à travers les lettres, une identité nationale. L'auteur remarque l'absence presque totale de la guerre dans cette littérature ou alors son exploitation par un discours de légitimation fort peu crédible et en conclut que ce thème historique fonctionne plutôt comme quête de légitimation du discours ou contestation de cette légitimité. Après avoir fixé les débuts de cette littérature au moment où la décolonisation a bouleversé une vision du monde, il analyse l'évolution des publics auxquels s'adressaient ces romans (intellectuels anticolonialistes, français plus ou moins ignorants de la réalité des pays colonisés, militants nationalistes). Il développe ensuite sa réflexion autour d'un corpus de trois œuvres: L'Incendie de Mohamed Dib, $L a$ Terre et le Sang de Mouloud Feraoun et Nedjma de Kateb Yacine. Dib raconte l'accession à l'Histoire par les paysans et s'interroge donc sur la nécessité de réfléchir à la relation entre un espace rural éloigné de l'histoire et un espace citadin où l'histoire se bâtit. Feraoun raconte l'irruption tragique de l'Histoire dans la temporalité d'un village traditionnel, à travers une relation amoureuse scandaleuse. Suivant Bonn, Yacine apporte enfin, avec son roman, un renouvellement radical du rapport à l'Histoire et subvertit le modèle romanesque traditionnel, en faisant de Nedjma-roman de la polyphonie et de l'ambiguïté-le véritable ouvrage fondateur de la littérature algérienne.

4 Espaces et localisation identitaire, développe le sujet de l'opposition entre les espaces ruraux, considérés a-temporels et a-historiques et celui de la ville coloniale, à l'historicité meurtrière. Les études sur la spatialité du et dans le roman algérien aboutissent, suivant l'auteur, à un non-lieu, à un échec donc de la quête identitaire liée à la localisation. L'attention portée aux écritures de l'émigration - qui se développent en Europe grâce à des écrivains nés de parents immigrés et qui voient l'émergence d'un nombre très significatif de femmes-met encore plus en crise la relation entre énonciation littéraire et localisation identitaire, en déstabilisant définitivement certains a-prioris sur cette littérature. Bonn observe également que cette production de la deuxième génération, en s'inscrivant dans la dissémination postmoderne, n'est pas arrivée à se constituer véritablement en groupe visible.

5 Le sens, errant ou absent affronte un autre thème central, celui de l'errance dans l'espace tout comme dans la signification. À travers des auteurs tels que Dib, Yacine ou Farès, l'auteur tente de montrer que l'errance de l'espace-représentée notamment par l'émigration - est aussi et surtout errance du sens, car elle est porteuse d'une ambiguïté irrésoluble. Érotique de l'écriture ou le roman familial de l'entre-deux langues, creuse enfin une réflexion sur l'écriture vue, par sa séduction, comme détournement des relations traditionnelles à l'Histoire mais aussi comme base de construction d'un nouveau type de roman familial. Le thème principal développé ici est celui de la rencontre entre langages, qui voit l'arabe littéraire succomber au français du colon, devant lequel les pères ont capitulé. La littérature algérienne se serait donc construite, suivant Charles Bonn, à partir d'un sacrifice fondateur, celui de la langue des parents, 
et se serait développée sur un entre-deux, pour enfin se mouler sur la langue et le genre littéraire de l'Autre, le roman.

6 Le volume se termine sur une section essentielle d'annexes comprenant les références bibliographiques des textes cités, un index des noms propres et un index des thèmes et des concepts évoqués dans l'ouvrage, ce qui facilite, de la part du lecteur, une consultation et un repérage rapides des informations. 